\title{
Light and lilacs: an interactive exploration of colorimetry
}

\section{Nicholas Kochan, Di Xu, Saleem Iqbal, Benjamin Moon, Janet Hrdina, et al.}

Nicholas S. Kochan, Di Xu, Saleem Iqbal, Benjamin Moon, Janet Hrdina, David Lippman, Saniat Ahmed Choudhury, Matthias T. Banet, Kaitlin J. Dunn, Ashan Ariyawansa Galabada Dewage, Robert Draham, Nicholas Takaki, Jennifer D. T. Kruschwitz, "Light and lilacs: an interactive exploration of colorimetry," Proc. SPIE 11143, Fifteenth Conference on Education and Training in Optics and Photonics: ETOP 2019, 111431N (2 July 2019); doi: $10.1117 / 12.2524624$

SPIE Event: Fifteenth Conference on Education and Training in Optics and Photonics: ETOP 2019, 2019, Quebec City, Quebec, Canada 


\title{
Light and lilacs: an interactive exploration of colorimetry \\ Nicholas S. Kochan*, Di Xu, Saleem Iqbal, Benjamin Moon, Janet Hrdina, David Lippman, Saniat Ahmed Choudhury, Matthias T. Banet, Kaitlin J. Dunn, Ashan Ariyawansa Galabada Dewage, Robert Draham, Nicholas Takaki, Jennifer D.T. Kruschwitz \\ The Institute of Optics, University of Rochester, Rochester NY 14620 USA
}

\begin{abstract}
The UNESCO International Day of Light, 16 May, serves to highlight the critical and diverse roles that light plays in our daily lives. Light has specific meaning to each local community, and finding that which has the greatest impact can be challenging. In the proper context, local festivals serve as a fertile ground for light appreciation, bringing together diverse local groups. We provide the devices for exploration of colorimetry, imaging, and color matching demonstrations at an otherwise social local festival. Methods of assembly and planning for the multi-day display are outlined.
\end{abstract}

Keywords: International Day of Light, Optics Outreach, Colorimetry

\section{STATEMENT OF PURPOSE}

At the time of writing, the authors are twelve graduate students and one faculty adviser and this project was completed as volunteer outreach work. The students are members of the outreach committee for the SPIE University of Rochester Student Chapter, and the faculty adviser an optics educator who is an expert in colorimetry. This report is written by students in the voice of students to show that large-scale community outreach may be adapted and made more accessible to other groups, including student groups. We detail community- and student-chapter-specific concerns so that other readers may consider these in adapting our methods to their needs.

\section{INTRODUCTION}

The UNESCO International Day of Light, 16 May, was inaugurated in 2018 as the day to recognize and celebrate the role that light plays in our day-to-day life from enabling science and technology to affecting art and culture. This day was established for people to share their experiences of light and, in so doing, share their traditions and understanding. In 2018, there were 87 participating countries around the world giving events and hosting events focusing on light-based science and technologies [1].

The celebration of the International Day of Light is a community activity and a chance to exchange new perspectives about what light means in the community. This gives optics experts a unique opportunity to educate the local community about the impact of optics and light. Furthermore, this is not only an opportunity for optics experts, it is also for the local resident community. This community often provides the critical infrastructure necessary for future optics careers. In Rochester, NY, the local community has a long history of supporting optics jobs and innovations. Large companies such as Kodak, Xerox, and Bausch \& Lomb laid the foundation for optics research and development in Rochester, each having considerable impact on the local community regarding optics education. Even though the Big Three do not have the economic impact they once held, they have given rise to a new generation of smaller companies, with many startups advancing critical optical technologies. Their contributions to our discipline are more diverse, and enable large community efforts not only in classical optics but also in areas of photonics, such as through the US National Photonics Initiative. This story of optics and photonics in Rochester is very relevant to a large part of the community and it compels us to connect with and give back to that community at-large.

In addition to deciding the people to influence for our outreach event, we had to consider our own individual optics identity. As graduate students of the SPIE University of Rochester Student Chapter, we have to manage different graduate student responsibilities. First year graduate students usually are taking courses and either graduating soon after with a Master's degree or preparing to enter into $\mathrm{PhD}$ research. Older $\mathrm{PhD}$ students are often occupied with their research and may feel

*nkochan@u.rochester.edu

Fifteenth Conference on Education and Training in Optics and Photonics: ETOP 2019, edited by

Anne-Sophie Poulin-Girard, Joseph A. Shaw, Proc. of SPIE Vol. 11143, 111431N · (c) 2019

SPIE, ICO, IEEE, OSA · CCC code: 0277-786X/19/\$18 · doi: 10.1117/12.2524624 
they have difficulty dealing with coordinated extracurricular activities in optics. To interface with our community, we had to be conscious of the concepts that would best enable the community to appreciate light. When our volunteer group was developing the action plan, we had to be cognizant of the amount of time and resources necessary to create and support a large-scale outreach event, on a volunteer basis, without detracting from research and other student responsibilities.

First, we describe the decision process of the organizing student committee to present at one of Rochester's largest festivals, the Rochester Lilac Festival. Then we describe detailed methods of reaching the target community, gathering volunteers and setting event logistics. Finally, we describe the specific exhibits and modes of publicity.

\section{REACHING EXHIBIT TARGET COMMUNITY}

The Rochester Lilac Festival is a free event with live music, rides and play areas, food and drink, and beautiful flowers. The audience attracts children, working adults and retirees, men and women, and people of all different professional backgrounds. The festival offers everyone the chance to come outside to enjoy the flowers and celebrate the coming spring and summer.

We needed to create an exhibit that would connect with a broad group of people. One way would be to appear like other exhibits at the festival and have a tent with professional graphics. Another way would be to have a vivid and interactive exhibit. Components of the exhibits were constructed in a tiered fashion to appeal to users with varying backgrounds and abilities (Figure 1). These mechanisms would then drive the structure of the exhibit. The goal was to have all individuals, from the very young to those more seasoned, able to experience the exhibit in their own way.
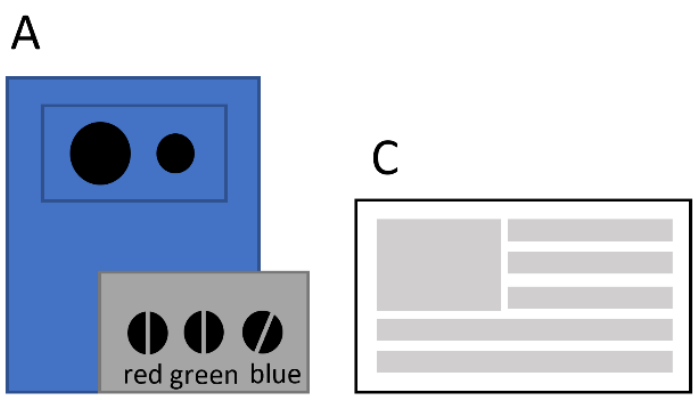

B

Figure 1. General schematic of outreach exhibit. Each exhibit consists of an optical device (A), a humaninteractive control component (B), and a descriptive plaque with text and images (C). In a casual setting most users interact with the optical device first, then adjust the knobs or buttons to understand the exhibit, and then read more about the display if interested. Exhibits are constructed following this user interaction model.

Each outreach exhibit consists of an optical device, a human-interactive control component, and a descriptive plaque with text and images. Every user expects different experiences from an educational optics exhibit. Very young children may come up to the exhibit and only look at the optical device. Older children and adults would perhaps observe while interacting with the knobs or buttons on the device. We wanted to engage each user such that they would be conducting a visual experiment without realizing it. Some attendees would read the descriptions if they were interested in familiarizing themselves with what was happening in the exhibit. Given that the exhibit was placed at a social festival, the assumption was that most people will not initially want to read the descriptive plaque. We ensured that there were colorful graphics with minimal jargon so that the exhibit would be accessible to new viewers.

While the strong presence of optics in the Rochester community was a driving factor in the event, we had to choose whether or not to make the event oriented around Rochester. Given that the festival celebrates flowers and springtime, we felt it best to align with the objectives of the festival and look at the science behind the enjoyment of those flowers. As such, the experience of the exhibits was more closely aligned with the experience that the festival attendees would expect, so our display would more likely relate with their overall festival experience. 


\section{VOLUNTEER COMMUNITY AND ORGANIZATION}

As the Lilac Festival is a ten-day event, we needed a large group of volunteers to ensure at least one person was in the tent at all times. Requiring volunteers meant it was critical to make the exhibits easy to operate with little to no prior training, and that we secured the exhibit in a very simple way so that it could be managed by just one person. We sourced volunteers from Rochester educational and professional communities. The Rochester optics community consists of three major institutions: University of Rochester, Rochester Institute of Technology, and Monroe Community College. There are also many surrounding companies which are part of local professional groups, with the primary group being the Rochester Local Section of the Optical Society. We reached out to all of these organizations to fill volunteer hours for the event.

There were 100-140 volunteer hours to fill throughout the run of the Lilac Festival. These hours were presented in twohour increments. We considered the volunteer shifts and volunteer shift management from the perspective of the volunteers and risk mitigation. Adjacent shifts overlapped each other by 30 minutes and accounted for slight potential schedule variations to render a seamless volunteer exchange. The event organizer was overseeing the whole festival and there were event committee members delegated to each day to ensure that volunteer shifts were filled. Volunteers received a tee shirt, and this also helped with the event engagement and publicity.

\section{OUTREACH DEMONSTRATIONS}

The display consisted of four exhibits: a color matching experiment, the color rendering of flowers (and other pigments) under different lighting conditions, thermal imaging, and smartphone microscopy. The last demonstration was inspired by an open source project [2] to "create a simple microscope." that may be coupled to smartphone cameras. The rest of the projects were constructed at the University of Rochester by subcommittees for the event. The demonstrations created in-house are displayed (Figure 2).
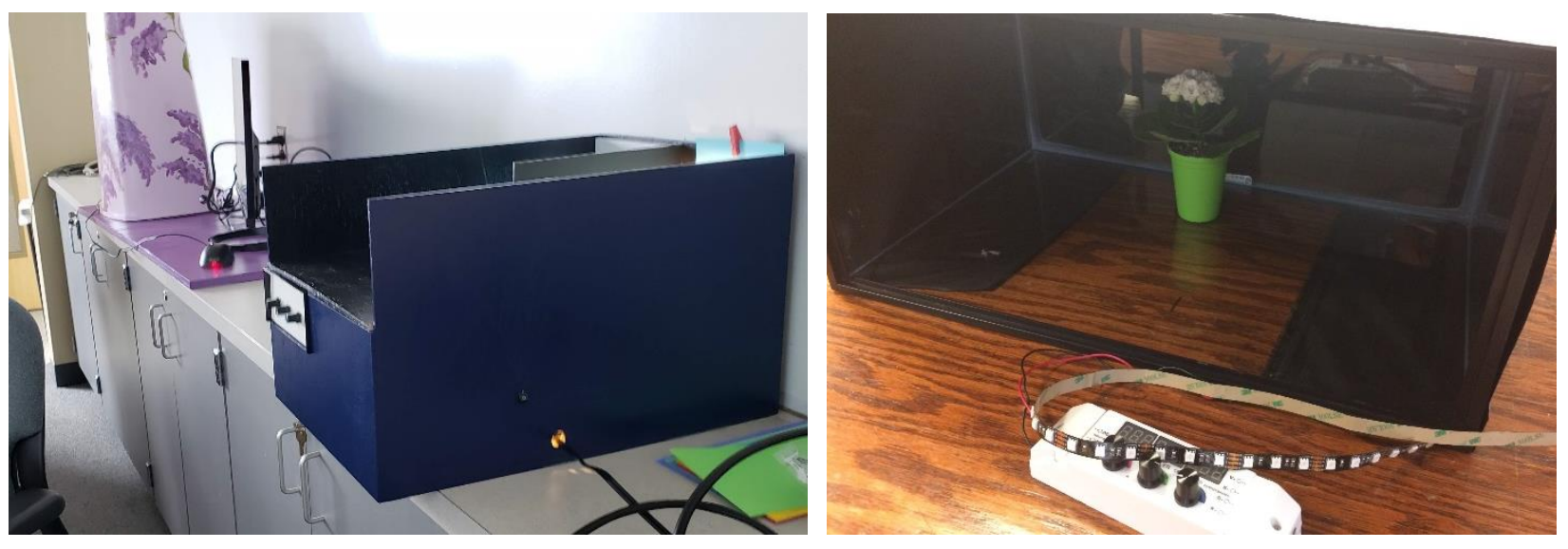

Figure 2. Demonstrations created at the University of Rochester for Lilac Festival outreach. Thermal imaging setup (left image, left), color matching box (left image, right), and flower pigment color rendering experiment (right image) are constructed.

The thermal camera setup was housed in a painted plastic container with a computer display showing the live feed from the camera. The FLIR-C2 thermal inspection camera was chosen for its compact size and rugged enclosure for outdoor events. The thermal subcommittee tested this camera while constructing its housing (Figure 3). The thermal camera showed how heat could be represented as visible color and the accompanying graphics emphasized its importance for better understanding our surroundings. 

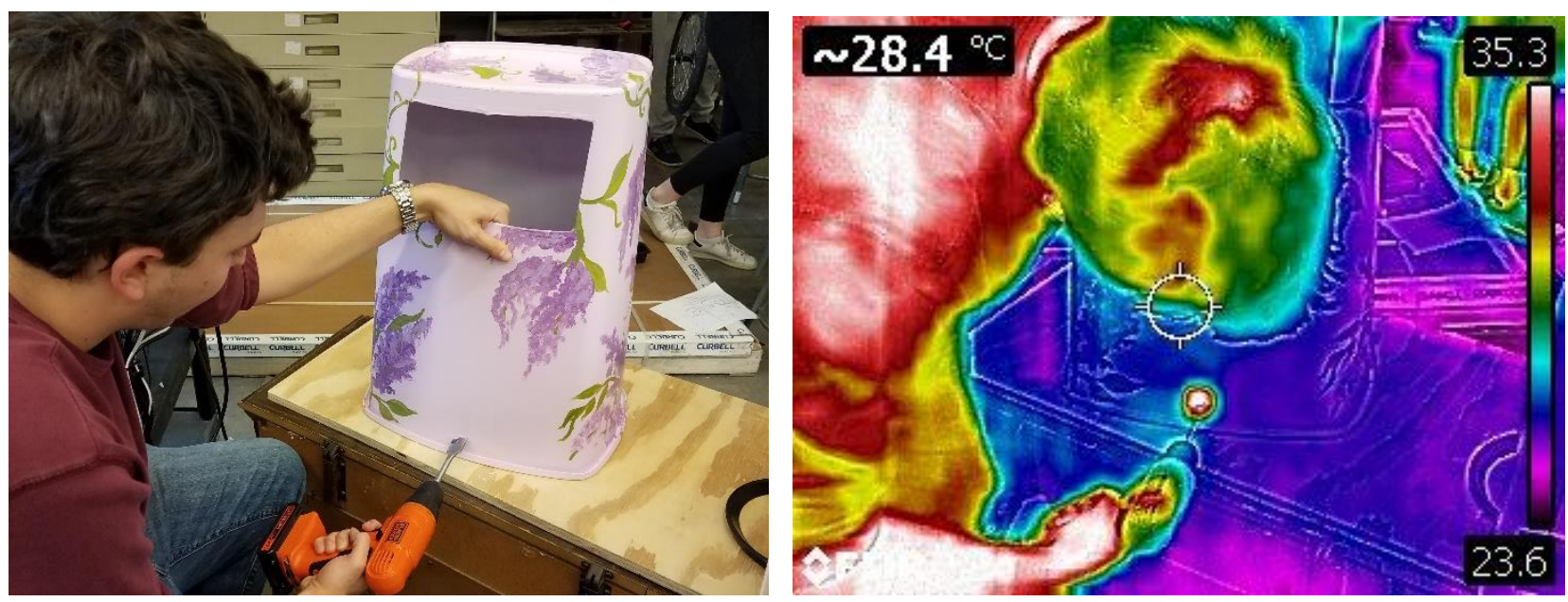

Figure 3: Thermal camera test. The thermal imaging subcommittee are building the housing for the thermal camera, and they image this construction using both a visible light camera (left) and the thermal camera to be used for the exhibit (right). Note the heat expended as the hole is drilled into the container is mapped to the visible spectrum. In the festival demonstration, such observations are used to describe basic thermal imaging and its applications.

The color matching experiment was crafted using high power LED lights wired through potentiometers to a power supply. The potentiometers served as user input to change the relative intensity of red, green, and blue light being projected onto the sample. The LED sources are combined with a simple singlet lens. The spatial separation of the LEDs in the housing meant there were slight non-uniformities in the color combining, which may serve as a point of discussion for the demonstration. Future iterations would seek to improve the color overlap. On the other side of a wooden separator, another commercial white LED source is projected onto a sample. The inside of the exhibit is painted black to prevent the wood affecting the spectral distribution of the source observed (Figure 4). The experiment has the user rotate the adjustment knobs until the perceived color from the matching sample is determined by the user to be the same between the two light sources. 

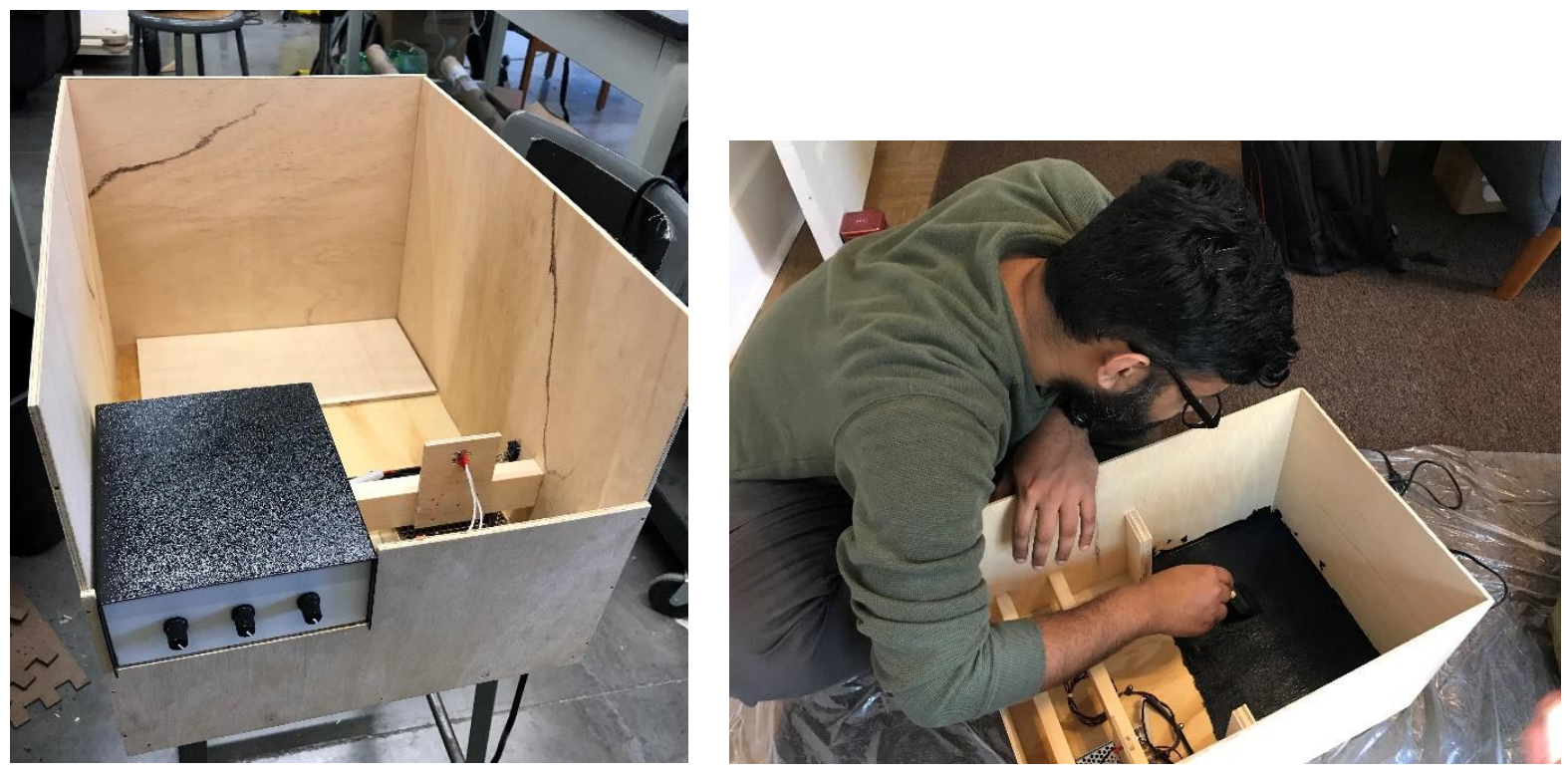

Figure 4. Unfinished color matching box and blackout painting. The unfinished color matching box (left) has tunable red, green, and blue LEDs and commercial light source mounted next to each other. A separator is placed between the sources to keep source spectra separate. To reduce the effect of wood spectral response on the light sources, the inside of the color matching box is painted black (right).

Finally, the flower color rendering experiment was built in an isolated box with LED strips and ultraviolet light. A covered fish tank was used as the structure for the exhibit to isolate the contents from outside light (Figure 5). The ultraviolet light allowed the viewer to see fluorescence while the LED light sources were tuned in a similar way to the color matching box. However, whereas the color matching box is used to compare an additive color mixture to match a specific sample, the flower color rendering exhibit looked at how changing the ratio of three colored lights emitted onto a variety of familiar objects could influence the colors that we see. 

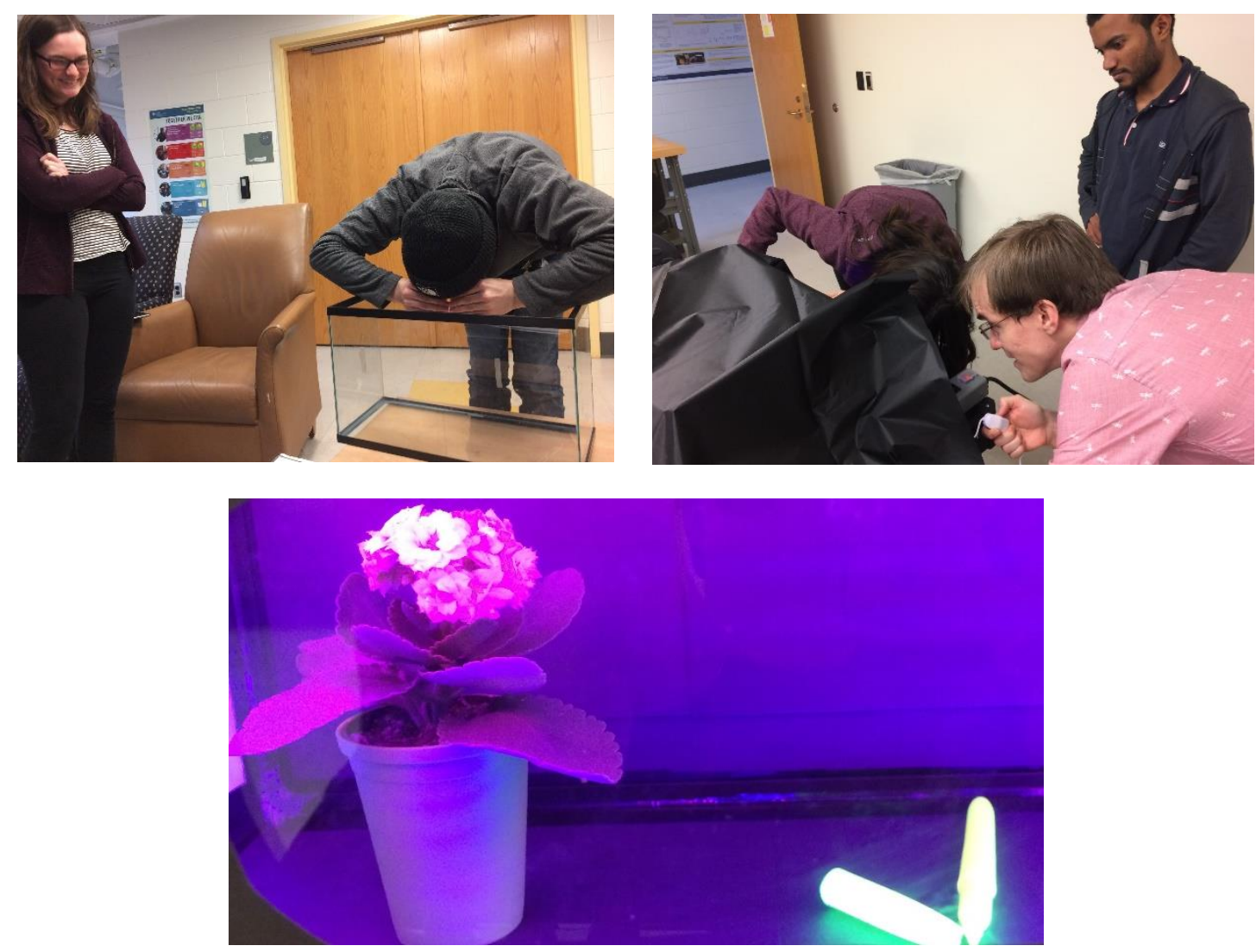

Figure 5. Flower color rendering construction. Students discussed how a fish tank would be used as the container for the flowers and other samples, and how the user would interact with it (upper left). Students cover and install lights for the exhibit (upper right) and first demonstration of the flower color response with from ultraviolet light was observed (lower center).

\section{PLANNING AND LOGISTICS}

The project planning overview and schedule is shown (Figure 6) and described here. Meetings to brainstorm for the project direction began in mid-Fall 2018. The project direction was subsequently established, the Lilac Festival contacted, and the budget created to begin applying for project funding in December 2018, as the project budget exceeded student chapter internal funds. Weekly meetings began January 2019 along with initial research for parts of exhibits. We also set in December and January a general timeline for all exhibits to be built through March and finalized by the beginning of April. This would allow regular communication with the Lilac Festival and publicity sources as necessary for around a month leading up to the event and some time for unexpected delays. Furthermore, this would leave all of April to be dedicated to logistical planning and organizing the exhibits. 


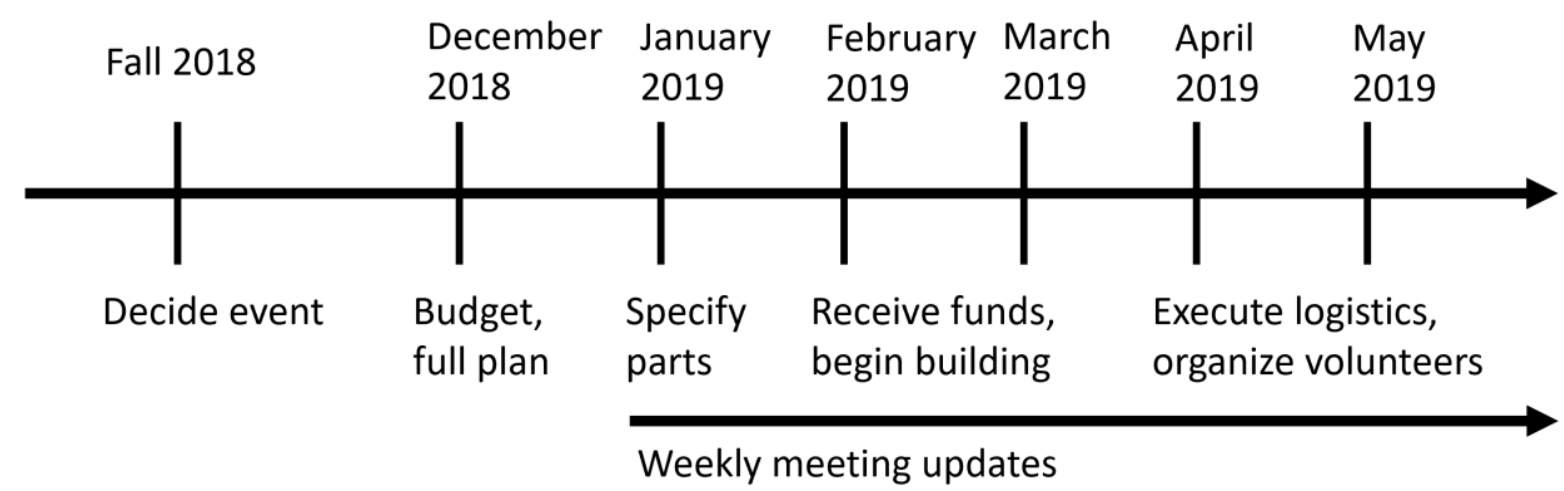

Figure 6. Schematic overview of event planning and schedule. Event planning spanned about seven months. Weekly meetings consisted of event planning details, budgeting, and event logistics.

Funding was secured February 2019 and components for the demonstrations were finalized and purchased FebruaryMarch. The majority of exhibit construction happened in March 2019, and most of the exhibits were completed by the beginning of April 2019. Through April, subcommittees developed the descriptive plaques for their displays and coordinated logistics for how their displays would be presented and maintained throughout the festival. Tee shirts and the tent were also designed and purchased in April.

The final steps were to check on publicity for the event and to coordinate resources for the Lilac Festival. We had to consider time in advance to coordinate this just before the event because the festival had to coordinate our exhibit with all other events at the festival. We also reached out to community volunteers to fill the 100-140 volunteer hours. We followed up on volunteer sign-ups with instructions on how to run exhibits and how to get tee shirts.

\section{PUBLICITY}

The modes of publicity must be considered in all stages of planning and construction. We could not rely on ourselves to publicize and construct this event in tandem due to time constraints. We recognized that we add unique value to the Lilac Festival as a new educational display, so the festival committee would help us publicize. We also knew that we were supported by local and international optics associations through our student chapter affiliation with the University of Rochester and SPIE. Communicating with these organizations about our exhibit was important for support of our event. The university, Lilac Festival, and optics professional organizations worked together with our group to publicize our event.

\section{ACKNOWLEDGEMENTS}

The authors recognize support of this project from SPIE, the international society for optics and photonics (SPIE IDL Micro Grant 2019), and the OSA Foundation.

\section{REFERENCES}

[1] UNESCO, "International Day of Light," [Online]. Available: https://www.lightday.org/copy-of-background.

[2] K. Yoshino, Instructables, [Online]. Available: https://www.instructables.com/id/10-Smartphone-to-digitalmicroscope-conversion/. 